\title{
Formal complexity in Digital Architecture
}

\author{
S. Hatzellis \\ School of Architecture, University of Technology, Sydney, Australia
}

\begin{abstract}
This paper discusses Geo_Soft's relationship to issues of aesthetics, complexity theory and technology. Complexity theory will be discussed insofar as its relationship to architecture is concerned, which will then lead into a review of the difference between Representation and Performativity. The recent semiotic tradition associated with post modern architectural writers of the 1960-1980s declared that the meaning of architecture was lost during the modernist period and that architecture should not break with its history. Performativity has been extended beyond the meaning given to it by Judith Butler. More specifically, the issue of complexity aesthetics will be analysed historically and critiqued by unveiling the differences between Venturi's 'Complexity and Contraction' and Le Corbusier's 'Towards a New Architecture', concurrently with the recent discourse regarding Performativity. A grading system for defining complexity will be explored by reference to the theory of the Edge of Chaos and finally, complexity will be explained through the pragmatic issues that emerged during the making of Geo_Soft, a rapid prototype sculpture.
\end{abstract}

Keywords: Complexity Theory, Performativity, Digital Architecture, Representation, Rapid Prototyping, Animation Software, Edge of Chaos.

\section{Complexity}

Digital Architecture has emerged from technological appropriation and as such has only recently started to develop a plausible theoretical discourse. Unlike most architectural styles at the end of the $20^{\text {th }}$ century that emerged from a theoretical agenda, Digital Architecture has post-rationalised its position in architectural discourse and has attempted to emancipate the discipline of architectural design from a linguistic and representational critique.

Complexity Theory is more then just the opposite of simplicity, it actively seeks to oppose it. Recent architectural design projects generated by exploration 
into advanced 3D animation software have been criticised for being unrealistic, un-constructible and incomprehensible. Part of the criticism aimed at recent digital exploration is that whilst the formal outputs from the computer are radically complex, this complexity is far too easily produced. This complexity appears chaotic and the randomness expresses no apparent purpose, cause or order. This lack of purpose is further used as criticism to define digital architecture as willful and without rigour or intellectual pursuit. However, the chaos inherent in digital architecture is a derivative of its unpredictability, both in its generation during the design process and in its appearance. And yet the forms generated by animation software are graphic constructs of mathematical algorithms which are rational. The apparent randomness of digital formal virtuosity is tied to the parametric and data based inputs that script the formal outcomes. But whilst this scripted, iterative and indexical architecture has the potential to produce a proliferation of formal outcomes, it nonetheless leaves the designer with the difficult role of selecting from a multiplicity of iterative forms.

Complexity can be further explained by illuminating its opposite, namely, simplicity. Simplicity often connotes beauty through the perception of balance and proportion and the cognition of a balanced form and structure that elicits attraction towards objects. This form of beauty, simple beauty, is easily understood by the viewer and allows for the visual consumption of the object without effort on the part of the viewer. Beauty can act in this way: by reducing the complexity of an object into easily definable characteristics, it requires little effort for the object's consumption.

Colin Rowe, in his seminal text 'Mathematics of the Ideal Villa' [3] made connections between the natural beauty of a Palladian villa with idealised beauty of Corbusier's Villa Savoye. Rowe put forward a connection between the two, namely, that both are geometrically derived, offering symmetry and mathematical proportions and are located within an unimpaired natural setting: in other words, order within chaos. But to accept this interpretation of beauty is to accept that architecture is opposed to nature. Humans seek simplicity because it reflects our misguided faith that underlying the nature of our universe is an elegant order. Prior to the digital age, simplicity was desirable as it was easier to calculate without errors. This is no longer the case as computers allow, within a certain range, extreme complexity in the areas of formulation, calculation and construction.

\section{From representation to performance}

Both Le Corbusier and Venturi sought to represent complexity in architecture as a mechanism to destabilise the status quo of their architectural period. In his 1966 publication "Complexity and Contradiction in Architecture" [1, p.18] Robert Venturi, in a half-veiled criticism of Le Corbusier's 1924 seminal text "Vers Une Architecture", argued that architecture should be "based on the richness and ambiguity of modern experience [due to the reality that] the wants of program, structure, mechanical equipment and expression....are diverse and conflicting in ways previously unimaginable" [2]. Both Venturi and Le 
Corbusier separately argued that the "the medium of architecture must be reexamined..." [1, p.18], however, whereas Le Corbusier argued for the programme of a building to be represented using abstract Plutonic forms, Venturi argued for the programme to be represented by "the variety inherent in the ambiguity of visual perception...". Venturi's arguments resided in Linguistic Complexity and are aimed at a richness of meaning in a multiplicity of signs, a semiotic architecture aligned with visual arts and literary critiques of the milieu of Postmodernism. Both Venturi and Le Corbusier have viewed architecture's role as a mode of representation, where a critique of architecture was aimed at satisfying a subjective interpretation of the building. Both also saw architecture as being 'viewed' and in this sense consumed. Whereas Le Corbusier sought to simplify the meaning of the programme by enclosing complex programmes in Plutonic solids, Venturi emphasised the complexity of inhabitation by displacing its cultural symbols to the façade. Venturi further postulated an argument that modern architectural projects required a multiplicity of symbols to absorb complexity and to create a rich multiplicity of meanings. His thesis insisted that architecture be critical by creating a set of visual clues that were understandable by society at large. This process of decoding the clues would then simultaneously function as a critique of high art. This reaction to Modernism connected Venturi to Pop Art rather than high art. Although these theories are still current in western architectural theory, the unfortunate architectural outcomes of this type of theory are that, in some instances, they have lead towards a historicist pastiche rather than a critical rethink of culture, history and its society. That is, the reality of society was only ever addressed as a set of images and the critique was representational rather than instrumental, understood only by architects rather than acting upon the intended public audience. Furthermore, this lack of instrumentality has once again lead to ineffectualness and a subsequent demise of historicity in critical architecture.

This is where Performativity has reinvigorated Post Modern thinking and posited the role of signs as active agents of change. As Judith Butler states, the words 'I now pronounce you man and wife' [4] changes the status of a couple within a community; those words actively change the existence of that couple by establishing a new marital reality: the words $d o$ something rather than merely represent something. It is in this act of doing that architecture can behave physically rather than just visually. Jesse Reiser [5], writing in 2000, while seeking to break with the semiotic approach argued that architecture should be performative and only secondarily representational. This belief in which Reiser called a 'complex ecology', stemmed from his exploration of digital design and bio-technological thinking. Reiser appropriated the concept of the 'Machinic Phylum' from French philosopher Gilles Deleuze who perceived life (and therefore architecture) as an overall set of self-organising processes where both organic and non-organic systems connected to create higher level entities. Reiser saw architecture as having reciprocity between its materiality and the human inhabitation: that is, the buildings are asked 'what they do' rather than 'what they mean'. This Performativity of affect can be modeled and tested within the virtual environment of digital space. 


\section{Performativity}

Although it is common to sideline digital architecture to the realm of technology, it has been the power of computer visualisation and the complexity of its formal language that has arguably surpassed previous architectural discourses. By creating a new genre of architecture that could not have been previously possible but for the use of new digital apparatuses, digital architects have re-initiated a debate regarding curvilinearity, expressionism and role of technology in society. In this respect, it is an area of design that is leading exploration into new forms of non-standard architecture. One of the most distinguishing and important features manifested in digital architecture is its performance-based essence.

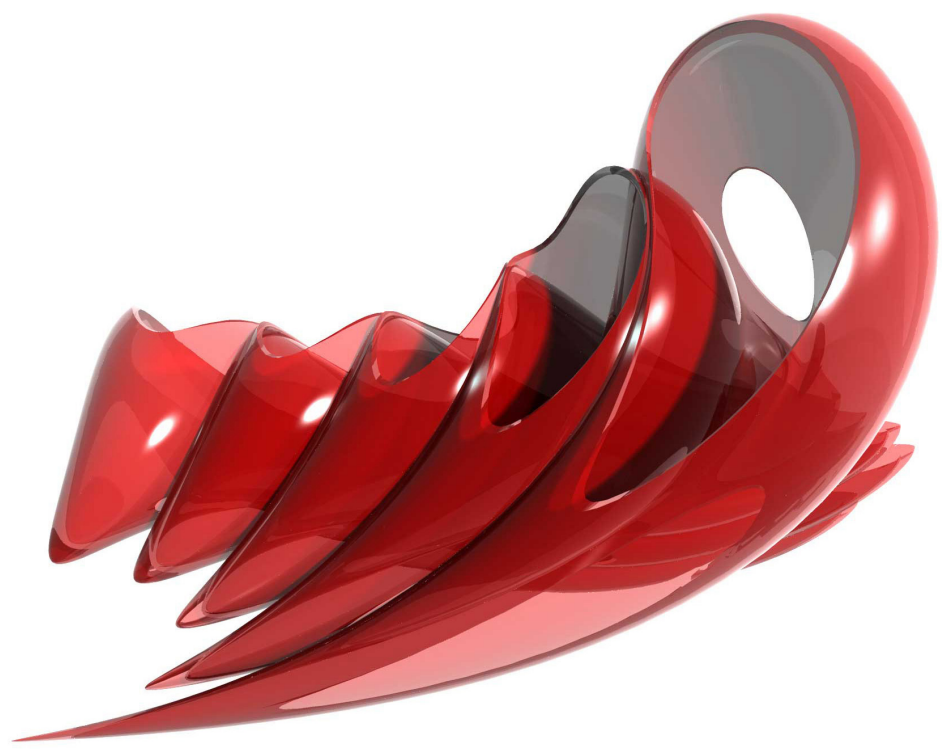

Figure 1: Geo_Soft, frame 231 from animation sequence.

Notwithstanding the relatively recent expansion in the use of digital technology in architectural practice, it is important to understand that digital architecture cannot be thought of as merely the new era of architecture that came straight after Post-Modernism (as Post-Modernism was commonly referred to as the movement that took place after Modernism). There is much evidence of digital architecture having connections to most periods of the $20^{\text {th }}$ century, including the much criticised and seemingly outmoded Modernism. Support of this statement can be found in some of the recent works of well-known digital architects including Zaha Hadid and UN Studio that are situated closer to Modernism insofar as their adherence to abstraction, geometry, formalism, structuralism and diagrammatic functionalism is concerned. And yet, this new form of modernism is not without meaning or history. Both Hadid's and van Berkel's work have similarities with late Italian Futurists and German 
Expressionism of the 1930s. Whilst some may view the connection of digital architecture with Modernism as disturbing (disturbing, because the author agrees with part of the critique leveled at modernism (and the return to it by digital architects) by the writers of the late 20th century including recent connections with Christopher Alexander's matrices, Utopianism, Form follows diagrams (function) to name a few), it only highlights the importance of reviewing digital architecture in a non-linear history rather then labeling it as an architecture that emerged after Post-Modernism. One of the main reasons digital architecture does not sit comfortably as being just another new movement in architecture is that it has borrowed and re-used ideas and objectives from other disciplines, including mathematics and science and is heavily reliant on the software of the graphic and entertainment industries. The exploration of design and technology by digital architects is paralleled in disciplines such as Information Technology, medical and astrophysical imaging, interaction design and naval and aerospace manufacturing.

\section{Geo_Soft - a case study}

Technology has underpinned the major shift in recent architectural debates regarding formal aesthetics and making. The ideological shift that has occurred due to the proliferation of digital software and hardware has influenced most areas of architectural education, including communications, construction, building science, design and, more recently, theory. At some stage it will also form part of architectural history. The balance of the paper will focus on the design and development of a sculpture produced for a 3D printed sculpture exhibition. This sculpture, entitled Geo_Soft (see figure 1 above) is demonstrative of how formal complexity can be used in architecture.

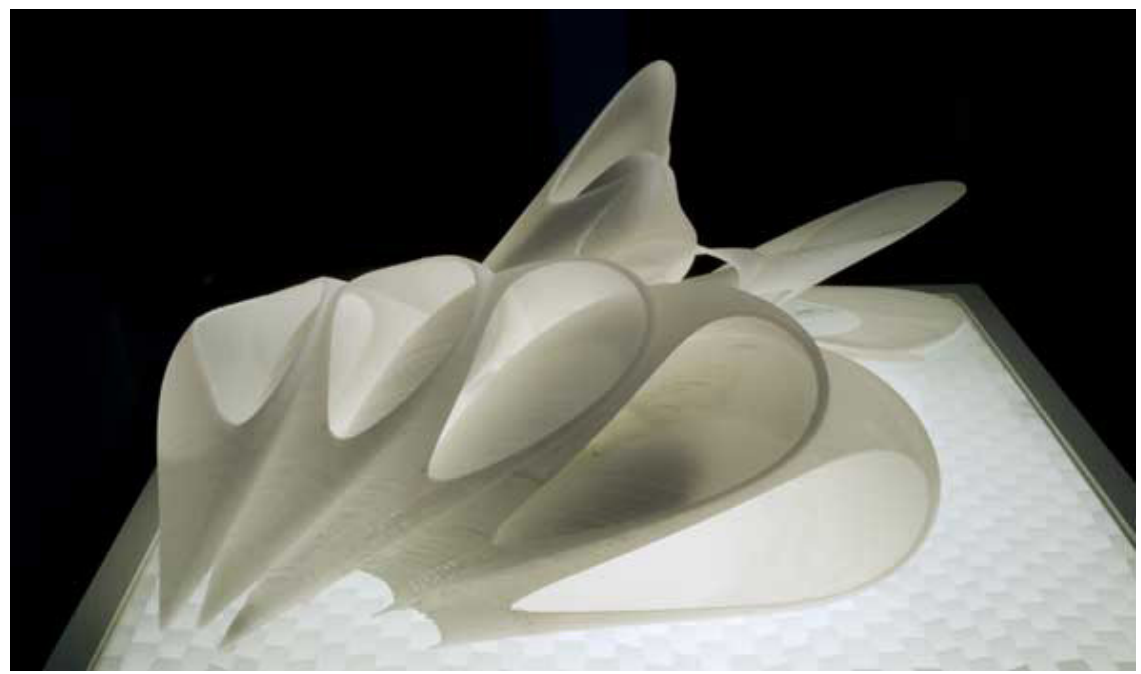

Figure 2: Geo_Soft, Rapid Prototype model. 
I was asked by the curators of the madeKnown exhibition to produce a sculpture that could be digitally manufactured using a 3D printer. The design process of the sculpture used digital technologies, including animation software and 3D ABS Rapid Prototypers, to fabricate a complex curvilinear object. The sculpture was conceived during a period of reflection about the theoretical and practical underpinnings of the $\mathrm{mDa}>\mathrm{lab}$, the new Master of Digital Architecture programme at the University of Technology, Sydney. Geo_Soft is a printed sculpture that resulted from digital exploration into formal complexity. The complexity of Geo_Soft is paradigmatic of digital technologies and design techniques that (mis)appropriate new media software as generative tools for nonstandard architecture. Geo Soft was conceived as a reconfigurable form that existed both as a conceptual and literal set of ideas. 'Soft' form may connote a malleable artifact that can physically be deformed but this was not the intent of this sculpture. Rather, it was seen as a means to develop a design approach that allowed the process of formation to be adaptive to inputs which would further allow for the absorption of a complex set of informational data and forces into the object. By creating a parametric design process it made possible the resistance to design closure and the maintenance of responsiveness to pragmatic and theoretical design requirements.

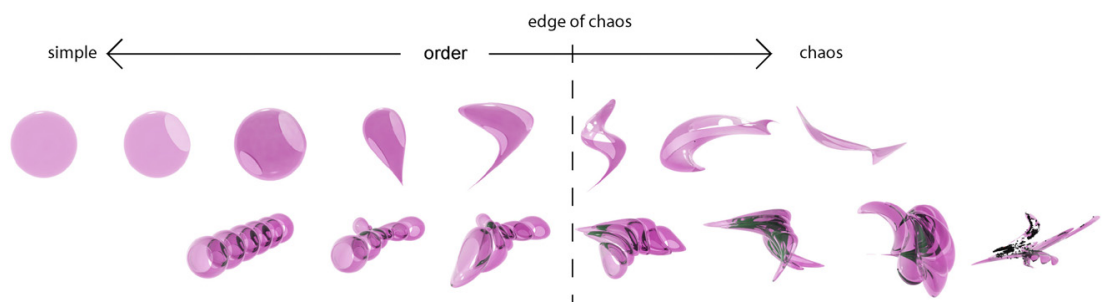

Figure 3: Frames from animation - from simple to chaotic form.

The design process set out to devolve the concept that beauty equates to Plutonic form and statics. This was achieved by starting with a geodesic sphere and deforming its surface's representation by means of mathematically controlled deformers which included twisting, bending and negative squashing by using parametric controlled deformers all within standard animation software. The complexity of Geo_Soft was derived from taking a geosphere and using a diagrammatic technique to develop and embed data-driven distortions into the previously undifferentiated system. However, not only was the sphere deformed, it was also possible to record the deformations over time, thereby creating an animation of the forces that acted on the object (see figure 3 above). This allowed for iteration of the object to be outputted from the animation as each frame of the movie had a distinct configuration. The process produced iterations that increased in formal complexity as the range and amount of inputs increased. Taking this design process to the next level revealed that complexity may be derived from a series of simple subsets or operations that multiply beyond the 
Edge of Chaos (the phrase originated from work by the mathematician C.G. Langton in 1990 to describe cellular automata and their ability for a higher level of self-organisation adjacent to a phase-change).

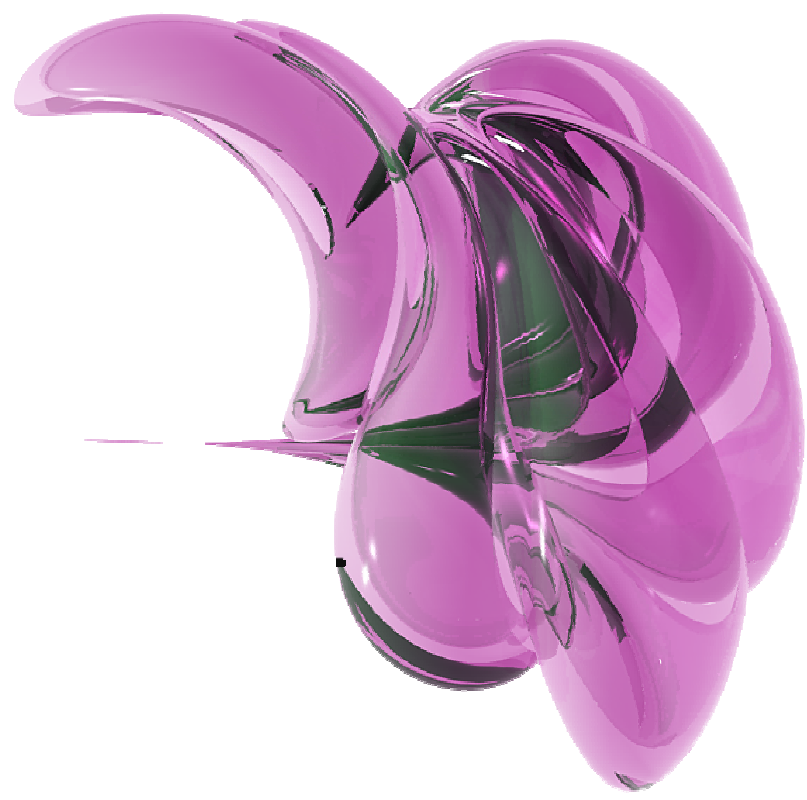

Figure 4: Chaos at Frame 97, darker areas show inverted non-manufacturable surfaces.

A state of chaos had not actually been reached with Geo_Soft: had it done so, it would have resulted in the object possessing inverted curves, lost vertices and multiple Blebs which would have made it un-manufacturable. Therefore, when the topological surface of the sphere curved to overlap itself and thus expose the internal face of the object, a new periodic rhythm and pattern emerged, hence creating an object that was beyond the Edge of Chaos. The first appearance of chaos is found in Geo_soft when its surface imperfects, including the introduction of ruptures, lost vertices or a Bleb. Each of these conditions cannot by printed using conventional 3D printers. The Bleb, as referred to in digital architecture, differs from the common meaning used in medicine for a bulbous protrusion on the surface of the eye filled with fluid. The Bleb has been described by Greg Lynn [6] as the virtual phase change when a deformed geometry is distorted to the point where its internal surface overlaps its external surface, giving the appearance of a bulbous cyst. This underside (inside or nonnormal) surface fails to produce surfaces that can be printed. Therefore, by resisting these surface imperfections and maintaining forms at the Edge of Chaos it was possible to seamlessly digitally manufacture this complex form (see figure 4 above). 
Building of formal complexity can now be produced by the construction industry as the components are manufacturable ex situ (in factories) rather then the traditional in situ method. If the $20^{\text {th }}$ century is synonymous with the repetitive forms of mass-produced Modernist buildings then the $21^{\text {st }}$ century will see the individuality of mass-customisation. The promise of rapid prototyping machines up-sizing to the scale of architecture no longer appears unbelievable. In the near future, one can foresee entire rooms, houses and even multistorey buildings being manufactured in factories using this method. Current machines can produce translucent and opaque objects that should suit requirements for walls, floors, ceilings, doors and windows. An architect will be able to design and print entire building components and then have them assembled in the factory only to be then transported to site and craned into position. Whilst some of this occurs now with the manufacture of standard components of buildings such as sheds, garages and large multi-storey componentry, what I am referring to is the design of architecturally unique spaces enveloped by 'custom-designed' formally complex shells. CADCAM (computer aided design and manufacturing) is prevalent in most manufacturing industries and will steadily emerge in the construction industry in the coming decades to allow mass-customisation of formally complex architecture.

\section{References}

[1] Venturi, R., Complexity and Contradiction in Architecture, Museum of Modern Art and Graham Foundation, 1966, second printing 2002.

[2] Le Corbusier, Towards a New Architecture, London, Dover Publications, 1986.

[3] Rowe, C, Mathematics of the Ideal Villa, Cambridge, Mass: MIT Press, 1976.

[4] Austin, J. L., How To Do Things With Words, ed. J. O. Urmson and Marina Sbisá. Cambridge, Mass.: Harvard University Press, 1962.

[5] Tschumi, B., \& Hugh D., Introduction chapter, Glass Ramps/Glass Wall, AA Publications, 2001.

[6] Greg Lynn Form, www.vagueterrain.net/content/archives/journal01/glf.html 